\title{
Brazilin isolated from Caesalpinia sappan L. inhibits rheumatoid arthritis activity in a type-II collagen induced arthritis mouse model
}

\author{
Eui-Gil Jung ${ }^{1}$, Kook-II Han ${ }^{1}$, Seon Gu Hwang ${ }^{1}$, Hyun-Jung Kwon², Bharat Bhusan Patnaik ${ }^{3,4}$, Yong Hyun Kim
} and Man-Deuk Han ${ }^{1 *}$

\begin{abstract}
Background: Caesalpinia sappan L. extracts exhibit great therapeutic potential, and have been shown to have analgesic and anti-inflammatory properties. This study aimed to understand the anti-rheumatoid activity of brazilin that was isolated from ethyl acetate extract of C. sappan L. The evaluations were conducted in mice with type-II collagen-induced arthritis (CIA).

Methods: Brazilin was purified via preparative HPLC and identified by mass spectrometry and ${ }^{1} \mathrm{H} /{ }^{13} \mathrm{C}$ NMR analysis. DBA/1J mice were divided into four groups $(n=10)$. Three groups of mice received intradermal injections of inducer bovine type-II collagen (BTIIC; 2 mg/ml in $0.05 \mathrm{ml}$ acetic acid) and $0.1 \mathrm{ml}$ of booster complete Freund's adjuvant (CFA). A second injection of BTIIC with booster incomplete Freund's adjuvant (ICFA) was given subsequently after 21 days. On 22nd day, purified brazilin (10 mg/kg body weight) or the disease-modifying anti-rheumatic drug methotrexate (3 mg/kg body weight) was administered intraperitoneally daily or every three days for 21 days, respectively to two groups of mice. At the $42 n d$ day, mice sera were collected, and the levels of pro-inflammatory cytokines and stress enzyme markers in serum were measured using standard immunoassay methods. The microstructure and morphometric analyses of the bones were assessed using high-resolution microfocal computed tomography.

Results: Brazilin isolated from C. sappan reduced the arthritis index score and the extent of acute inflammatory paw edema in CIA-mice. The bone mineral density was significantly $(p<0.05)$ lower in only-CIA mice, and appeared to increase commensurate with methotrexate and brazilin administration. Brazilin prevented joint destruction, surface erosion, and enhanced bone formation as revealed by microstructural examinations. Brazilin markedly attenuated mouse CIA and reduced the serum levels of inflammatory cytokines including TNF-a, IL-1 $\beta$, and IL-6.
\end{abstract}

Conclusions: Brazilin purified from C. sappan L. shows protective efficacy in CIA mouse, and may be useful to treat chronic inflammatory disorders including rheumatoid arthritis.

Keywords: Caesalpinia sappan, Rheumatoid arthritis, Collagen-induced arthritis, Brazilin, Pro-inflammatory cytokines

\section{Background}

Rheumatoid arthritis (RA) is a systemic inflammatory disease of the synovium, cartilage, and bone. RA causes persistent pain, stiffness, swelling, deformities, and loss of joint function [1,2]. Although RA is not inherited, certain human RA susceptible genes may be triggered in response to infection or environmental factors, establishing an

\footnotetext{
* Correspondence: mdhanpro61@gmail.com

'Department of Life Science and Biotechnology, Soonchunhyang University, Asan, Chungnam 336-745, Republic of Korea

Full list of author information is available at the end of the article
}

autoimmune condition wherein the immune system begins to produce substances that attack the joints. Such substances include interleukin-1 (IL-1) and tumor necrosis factor alpha (TNF- $\alpha$ ); these factors damage articular cartilage and bone [3]. Some reports have documented the synthesis of novel cytokines including IL-17, IL-18, and RANK ligand in the synovium, which secretes enzymes degrading proteoglycans and collagen, in turn causing bone loss $[4,5]$.

The worldwide prevalence of RA is $0.5-1 \%$ [6], and $\mathrm{RA}$ is threefold more prevalent in females than in males.

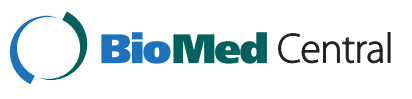

(c) 2015 Jung et al.; licensee BioMed Central. This is an Open Access article distributed under the terms of the Creative Commons Attribution License (http://creativecommons.org/licenses/by/4.0), which permits unrestricted use, distribution, and reproduction in any medium, provided the original work is properly credited. The Creative Commons Public Domain Dedication waiver (http://creativecommons.org/publicdomain/zero/1.0/) applies to the data made available in this article, unless otherwise stated. 
Three general classes of drugs have been recommended to treat RA; these are non-steroidal anti-inflammatory agents (NSAIDs), corticosteroids, and disease-modifying antirheumatic drugs (DMARDs). Although all of these drugs reduce acute inflammation and pain, they do not change the course of the disease or prevent joint destruction. Additionally, drug side-effects include increased risks of malignancy and gastrointestinal disturbances. These sideeffects and the high drug costs mitigate against prolonged drug use [7].

Methotrexate (MTX) is a DMARD, and is classified pharmacologically as an anti-folic-acid because the drug antagonizes folic-acid metabolism [8,9]. MTX not only reduces pain and swelling in the joints, but also its damage and long-term disability. However, the side-effects include liver functional abnormalities, lung disorders, stomatitis, skin rashes, hematological diseases, and pancytopenia. In short, MTX must be administered only with care. To compensate for the adverse effects of MTX and other drugs, and to devise cost-efficient RA treatment strategies, attention has recently been diverted to the study of useful natural compounds derived from herbal plants [10]. Several recent studies have focused on herbal extracts or compounds that exhibit anti-arthritic effects in rats with adjuvant-induced arthritis [11-13].

Caesalpinia sappan L. (Leguminosae) is a traditional medicinal plant distributed in the Asian peninsula including India, Burma, Vietnam, Sri Lanka, and China. The dried heartwood of C. sappan L. exhibits various pharmacological effects, including anti-hyperglycemic, anti-hypercholesterolemic, anti-hepatotoxic, anti-inflamma tory, and sedative activities [14-18]. The immunomodulatory, anti-inflammatory, and antioxidant activities of C. sappan extracts suggest its potential role in exerting antiarthritic effects.

In the present study, we extracted and characterized a major component of the dried heartwood of C. sappan; brazilin (7,11b-dihydrobenz $[b]$ indeno $[1,2-d]$ pyran$3,6 a, 9,10(6 \mathrm{H})$-tetrol). This is a natural red pigment with both anti-inflammatory and anticancer activities $[17,19]$. We explored whether brazilin purified from C. sappan could be used to treat type-II collagen-induced arthritis (CIA) in a mouse model of RA.

\section{Methods}

\section{Plant materials and isolation of the compound}

Dried heartwood of C. sappan L. was purchased from the Kyungdong Local Market, Seoul, Korea in March 2012. A voucher specimen (No. SCHB 12-015) was deposited at the Herbarium of College of Natural Science, Soonchunhyang University and authenticated by Dr. B.Y. Lee from National Institute of Biological Resources, South Korea.

Air-dried and chipped C. sappan (6 kg) was extracted with $95 \%(\mathrm{v} / \mathrm{v})$ methanol for $72 \mathrm{~h}$. The extract was filtered through a Buchner funnel fitted with Whatman No. 1 filter paper, concentrated in a rotary evaporator operating under reduced pressure, and subsequently diluted in water. This preparation was further fractionated into hexane $(3 \times 1,000 \mathrm{ml})$, chloroform $(3 \times 1,000 \mathrm{ml})$, ethyl acetate $(3 \times 1,000 \mathrm{ml})$, and butanol saturated with water $(3 \times 1,000 \mathrm{ml})$ extracts. Each extract, and the aqueous phase remaining after all extractions, was dried under reduced pressure to yield a hexane $(1.13 \mathrm{~g})$, a chloroform (7.05 g), an ethyl acetate (176.94 g), a butanol $(8.26 \mathrm{~g})$, and a water fraction $(4.35 \mathrm{~g})$.

The ethyl acetate soluble fraction $(170 \mathrm{~g})$ was purified by column chromatography (CC) on a Sephadex LH-20 matrix, and yielded five fractions $(\mathrm{C}-1 \sim \mathrm{C}-5)$. Fraction C-4 $(7.31 \mathrm{~g})$ was further separated by $\mathrm{CC}$ on a Sephadex LH-20 matrix, using $\mathrm{CHCl}_{3}: \mathrm{MeOH}(20: 1, \mathrm{v} / \mathrm{v})$, to generate fractions C-4-1 C-4-4 [19]. Fraction C-4-3 (3.54 g) was separated via silica gel $\mathrm{CC}$, using $\mathrm{CHCl}_{3}$ : EtOAc (7:3, 5:5, 3:7), to yield three fractions. Fraction C-4-3-2 (401 mg) was again purified via silica gel CC using $\mathrm{CHCl}_{3}$ : EtOAc $(7: 3,5: 5)$ to yield fractions C-4-3-2-1 and C-4-3-2-2. The effective ingredient in fraction C-4-3-2-1 was confirmed to be brazilin.

\section{High-performance liquid chromatography (HPLC)}

Brazilin was purified from C. sappan extract using a preparative LC-20 series HPLC system (Shimadzu Corp., Tokyo, Japan) fitted with a reverse-phase $C_{18}$ column (UG120, 5- $\mu \mathrm{m}$ particle sizes, 4.6 I.D. x $250 \mathrm{~mm}$ UG120, Shiseido, Japan) with monitoring of eluate absorbance at $280 \mathrm{~nm}$. The eluent system consisted of an isocratic mode of $100 \%(\mathrm{v} / \mathrm{v})$ methanol, running at a flow rate of $0.5 \mathrm{ml} / \mathrm{min}$ at a column temperature of $25^{\circ} \mathrm{C}$. Fraction with retention times of about 7.669 were amalgamated from repeat HPLC runs.

\section{Spectrometric identification of the compound}

A liquid chromatography-mass spectrometry-ion trap-time of flight (LCMS-IT-TOF) mass spectrometer (Shimadzu Corporation, Tokyo, Japan) was used for mass spectrometric evaluation of the positive and negative ion mode masses and to record MS/MS spectra. The detection voltage and interface temperature were $1.60 \mathrm{~V}$ and $400^{\circ} \mathrm{C}$ respectively.

${ }^{1} \mathrm{H}$ nuclear magnetic resonance (NMR) and ${ }^{13} \mathrm{C}$ NMR spectra were obtained with the aid of a JNM-LA 400 NMR (Jeol Ltd., Tokyo, Japan) operating at $100 \mathrm{MHz}$, using $\mathrm{CD}_{3} \mathrm{OD}$ as solvent. Chemical shifts are reported in parts per million (ppm) downfield from those of an internal tetramethylsilane (TMS) standard.

\section{Drugs and experimental animals}

Brazilin was kept in brown glass bottle and a vacuum container. The extract was stored at $4^{\circ} \mathrm{C}$ until further use. Brazilin and MTX were dissolved in a small volume 
of dimethylsulfoxide (DMSO) and its concentration was adjusted to working concentration with $0.9 \%$ saline for animal administration. The final concentration of DMSO was set to $0.1 \%$.

Arthritis was induced in 7-week-old male DBA/1J mice (body weight 20-23 g; Central Laboratory, Animal Inc., Seoul, Korea), and were prospectively randomized into normal, control, and treatment groups. The animals were acclimated under standard laboratory conditions of $22 \pm 2^{\circ} \mathrm{C}$ ambient temperature, relative humidity of $60 \pm$ $5 \%$ under a daily $12 \mathrm{~h}$ light: dark cycle. All mice had free access to tap water and a laboratory diet [crude protein NLT 20.5\%, crude fat NLT 3.5\%, crude fiber NMT 8.0\%, crude ash NMT $8.0 \%$, Ca NLT $0.5 \%$, and phosphorus NLT $0.5 \%$ (all w/w)]. After 7 days of acclimatization, mice were used in experiments. The study was conducted with the consent of the Ethics Committee for the use of experimental animals as authorized by the Animal Research Center of Soonchunhyang University (Approval number: SCH13_08_03).

\section{Induction of $\mathrm{ClA}$}

$\mathrm{DBA} / 1 \mathrm{~J}$ mice were injected intradermally twice (each of $100 \mu \mathrm{g}$ ) with bovine type-II collagen (Central Lab, Seoul, Korea) dissolved overnight at $4^{\circ} \mathrm{C}$ in $0.05 \mathrm{M}$ acetic acid $(2 \mathrm{mg} / \mathrm{ml})$, and subsequently emulsified in an equal volume of complete Freund's adjuvant (CFA, Sigma-Aldrich, St. Louis, MO, USA) at day 0 (primary immunization), and incomplete Freund's adjuvant (ICFA, Sigma-Aldrich, St. Louis, MO, USA) at day 21 (2nd booster injection) [20]. The animals were randomly divided into four groups of approximately equal mean body weight $(n=10$ per group). It included normal group without immunization or CIA, control group with saline injection after CIA, and experimental groups with intraperitoneal injections of anti-rheumatoid drug, methotrexate $(3 \mathrm{mg} / \mathrm{kg}$ of mouse body weight; $0.2 \mathrm{~mL})$ every $3 \mathrm{rd}$ day and brazilin $(10 \mathrm{mg} / \mathrm{kg}$ of mouse body weight; $0.2 \mathrm{~mL}$ ) daily from day 22 to day 42 after 2 nd booster injection.

\section{Clinical scoring of arthritis}

CIA mice were evaluated by two independent observers three-to-four times in a week, with regards to the extent of all the inflammation, erythema, edema of the periarticular tissues, and enlargement, distortion, or ankylosis of the joints. Each paw was scored on a scale of 0-4 (an arthritis index), where 0 indicated inflammation; 1 edema or erythema of one joint; 2 edema or erythema of two joints (whether of one or two digits); 3 edema or erythema of more than two joints (whether of one, two, or three digits); and 4 severe arthritis of the entire paw or all digits [21]. Each total arthritis score was the sum of the scores for all four limbs (the maximum possible score was thus 16). Each arthritis index was derived by two independent observers blinded to treatment mode. Paw thickness was measured at least three-to-four times per week, to monitor footpad swelling. The thickness of the paw was measured using a Vernier calliper (Ozaki, Tokyo, Japan) at least 3 times a week for footpad swelling. Each mouse was weighed 2 times a week.

\section{Microstructural bone examination using microfocal computed tomography (micro-CT)}

The microstructures of the distal end of the left femur, the proximal end of the left tibia, the distal end of the left calcaneus, and the distal end of the left second metatarsal bone, were analyzed via high resolution micro-CT (SkyScan 1172, Bruker, Antwerp, Belgium). Bone mineral density (BMD) was determined by running metaphyseal scans at points $3 \%$ along the length of each bone. The slice pitch was $20 \mu \mathrm{m}$, and 50 slices were analyzed. The two-dimensional images thus obtained were converted to three-dimensional images, and bone microstructure was evaluated. The parameters recorded were: bone volume (in $\mathrm{mm}^{3}$ ) relative to tissue volume (in $\mathrm{mm}^{3}$ ) (expressed as a percentage); bone surface (in $\mathrm{mm}^{2}$ ) relative to bone volume (in $\mathrm{mm}^{3}$ ) (expressed per $\mathrm{mm}$ ); trabecular thickness (in $\mathrm{mm}$ ); trabecular number (in $\mathrm{mm}^{-1}$ ), and fractal dimension.

\section{Serum biochemical analysis}

The serum levels of the proinflammatory cytokines TNF- $\alpha$, IL-1 $\beta$, and IL- 6 were measured using mouse immunoassay kits (IL-1ß: ML800C; TNF- $\alpha$ : MTA00B; and IL-6: M6000B; R\&D Systems, Minneapolis, MN) according to the manufacturer's instructions. The levels of enzyme markers of stress, including aspartate aminotransferase (AST), alanine aminotransferase (ALT), alkaline phosphatase (ALP), and creatinine levels were measured on a Synchron LX-20 Clinical System (Beckman Coulter Inc., Brea, CA).

\section{Statistical analysis}

Statistical analysis featured one-way analysis of variance. All experimental values are expressed as means \pm standard errors. Between groups comparisons were performed using the post-hoc Tukey test. $p<0.05$ was considered to indicate significance.

\section{Results}

\section{Purification and characterization of brazilin}

The ethyl acetate extract of $C$. sappan heartwood was repeatedly extracted with $\mathrm{CHCl}_{3}: \mathrm{MeOH}$ and subjected to Sephadex and silica gel column chromatography to obtain a single final fraction (Figure 1), later identified to contain brazilin which exerted anti-RA effects in the mouse CIA model. Brazilin formed a single homogenous peak under preparative HPLC conditions, with a retention time of $7.669 \mathrm{~min}$ (Figure 2A). The purity of 

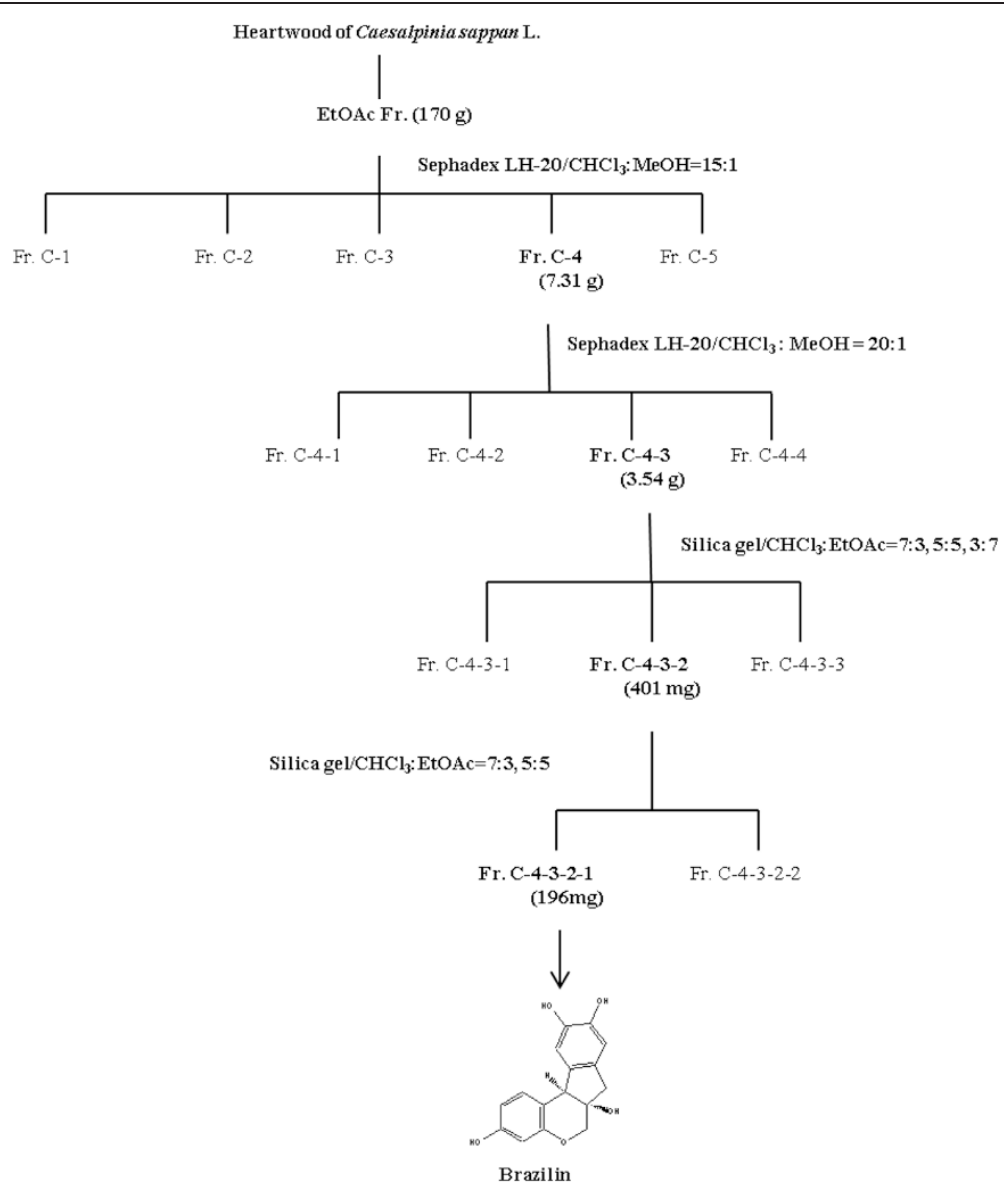

Figure 1 Schematic diagram illustrating the sequential purification of brazilin $(7,11 b$-dihydrobenz [b] indeno [1,2- $d]$ pyran-3,6a,9,10(6H)-tetrol) from methanol extract of Caesalpinia sappan L. The chemical structure of brazilin is shown below.

brazilin was determined to be above $98 \%$ according to HPLC conditions. LCMS-IT-TOF mass spectrometry yielded the elemental composition and molecular weight of brazilin which had a positive ion mass of $287.0733 \mathrm{~m} / \mathrm{z}$ and a negative ion mass of $285.0584 \mathrm{~m} / \mathrm{z}$ (Figure 2B).

We used ${ }^{1} \mathrm{H}$-NMR (Figure $3 \mathrm{~A}$ ) and ${ }^{13} \mathrm{C}$-NMR (Figure 3B) to derive the chemical structure of brazilin. ${ }^{1} \mathrm{H}-\mathrm{NMR}$ data: $\left(400 \mathrm{MHz}, \mathrm{CD}_{3} \mathrm{OD}\right) \delta: 7.19(1 \mathrm{H}, \mathrm{d}, J=5.6 \mathrm{~Hz}, \mathrm{H}-1), 6.77$ $(1 \mathrm{H}$, br s, H-8), $6.65(1 \mathrm{H}$, br s, H-11), $6.49(1 \mathrm{H}, \mathrm{dd}, J=11$ and $1.6 \mathrm{~Hz}, \mathrm{H}-2), 6.30(1 \mathrm{H}, \mathrm{d}, J=1.6 \mathrm{~Hz}, \mathrm{H}-4), 3.98$ $(1 \mathrm{H}$, br s, $\mathrm{H}-12), 3.93(1 \mathrm{H}, \mathrm{dd}, J=7.2$ and $0.8 \mathrm{~Hz}, \mathrm{H}-6 \mathrm{a})$, $3.71(1 \mathrm{H}, \mathrm{d}, J=7.2, \mathrm{H}-6 \mathrm{~b}), 3.00(1 \mathrm{H}, \mathrm{d}, J=10.4 \mathrm{~Hz}, \mathrm{H}-7)$ and $2.81(1 \mathrm{H}, \mathrm{d}, J=10.4 \mathrm{~Hz}, \mathrm{H}-7 \mathrm{~b})$. The ${ }^{13} \mathrm{C}-\mathrm{NMR}$ data: (100 MHz, CD $\left.{ }_{3} \mathrm{OD}\right) \delta 43.00$ (C-4a), 51.24 (C-3), 70.92 (C-9), 77.84 (C-10), 104.08 (C-11a), 109.71 (C-1), 112.42 (C-7a), 112.74 (C-1a), 115.69 (C-8), 131.59 (C-11), 132.09 (C-2), 137.51 (C-4), 144.89 (C-6a), 145.23 (C-6), 155.64 (C-12), and $157.71(\mathrm{C}-7)$.

\section{Effects of brazilin on mouse CIA}

Body weight decreased significantly by day 25 in mice that developed arthritis, regardless of whether such animals received brazilin or MTX (Figure 4A). No significant difference was evident among the three collagen-sensitized groups. Paw swelling was most severe (upto $3.0 \mathrm{~mm}$ ) in the CIA-induced control group, at day 30. A steep increase in swelling was observed from day 20-30 in control group; followed by a minor decline (Figure 4B). However, marked reductions in paw swelling was evident after intraperitoneal injection of either MTX or brazilin, compared with the control group. The extent of swelling was less in MTX than brazilintreated mice on day 42. The gross lesions in the foot of collagen-induced control group mice (Figure 4C-ii) was severe, but was lesser in MTX (Figure 4C-iii) and brazilin-treated groups (Figure 4C-iv). Arthritis scores attained their maxima by day 42 in all mouse groups (Figure 4D), and were similar at all time-points after sensitization, in mice administered either MTX or brazilin. Thus, no between-group difference was found to be significant.

The volumetric BMDs of CIA-induced mice were recorded (Figure 5). The BMD of the proximal part of the left tibial metaphysis (Figure 5-i), the distal part of the 

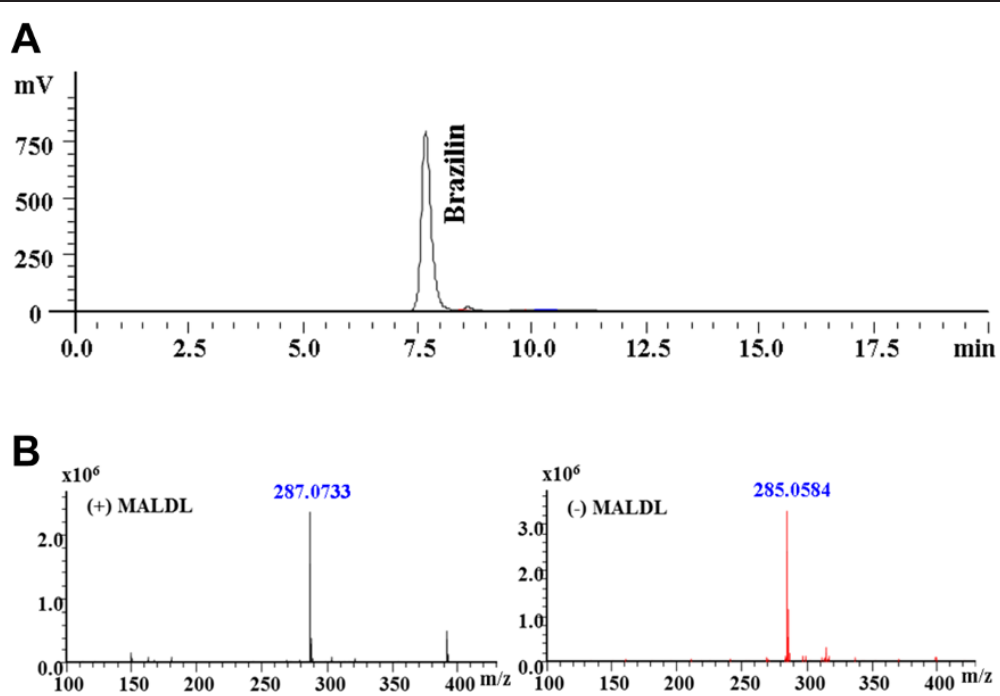

Figure 2 Purification and characterization of brazilin from Caesalpinia sappan L. extracts. (A) Preparative HPLC profile of purified brazilin from C. sappan extract. A reverse phase C18 column $(4.6 \times 250 \mathrm{~mm}$ ) was used for analysis, and eluted with $100 \%$ methanol in isocratic mode with flow rate of $0.5 \mathrm{ml} / \mathrm{min}$ and detection wavelength of $280 \mathrm{~nm}$. A near-homogenous peak with a retention time of $7.669 \mathrm{~min}$ was observed. (B) MALDI-TOF mass spectra of brazilin from C. sappan L. The optimal collision energy was $45 \mathrm{eV}$ in the mass range $\mathrm{m} / \mathrm{z} 100$ to $\mathrm{m} / \mathrm{z} 450$. The detection voltage and interface temperature were set to $1.60 \mathrm{~V}$ and $400^{\circ} \mathrm{C}$. Methanol was used as the mobile phase.

left femoral metaphysis (Figure 5-ii), the distal part of the left calcaneous (Figure 5-iii), and the distal part of the left second metatarsal bone (Figure 5-iv), were significantly lower in the control group than in other groups $(p<0.05)$. Administration of brazilin to CIA-induced mice significantly increased the BMD of the distal part of the left calcaneous. The decrease in BMD of the control group was not notably affected when either MTX or brazilin was administered. Micro-CT analysis of the tibial metaphysis, the femoral metaphysic, and the left leg are shown in Figure 6. The left tibial metaphysis and the distal part of the left femur of the control group were thin and distorted, compared with those of the normal group. The proximal part of the left tibial metaphysis
(Figure 6A), and the distal part of the left femur (Figure 6B) were not so affected in the brazilin and MTX groups. Thus, administration of brazilin more effectively preserved trabecular architecture than did MTX.

The bone volume (BV)/tissue volume (TV) ratios were significantly lower in the control and MTX-treated mice with CIA than in the brazilin-treated group $(p<0.05)$ (Table 1). The bone surface (BS)/bone volume (BV) ratio was higher in the control group, although the trabecular thickness (Tb-Th) was significantly lower. The BS/BV ratio was significantly lower in the brazilin treated group than the normal non-CIA-induced group. The normal $\mathrm{Tb}-\mathrm{Th}$ ratio was higher than those of the MTX and brazilin-treated groups $(p<0.05)$. The extent of trabecular

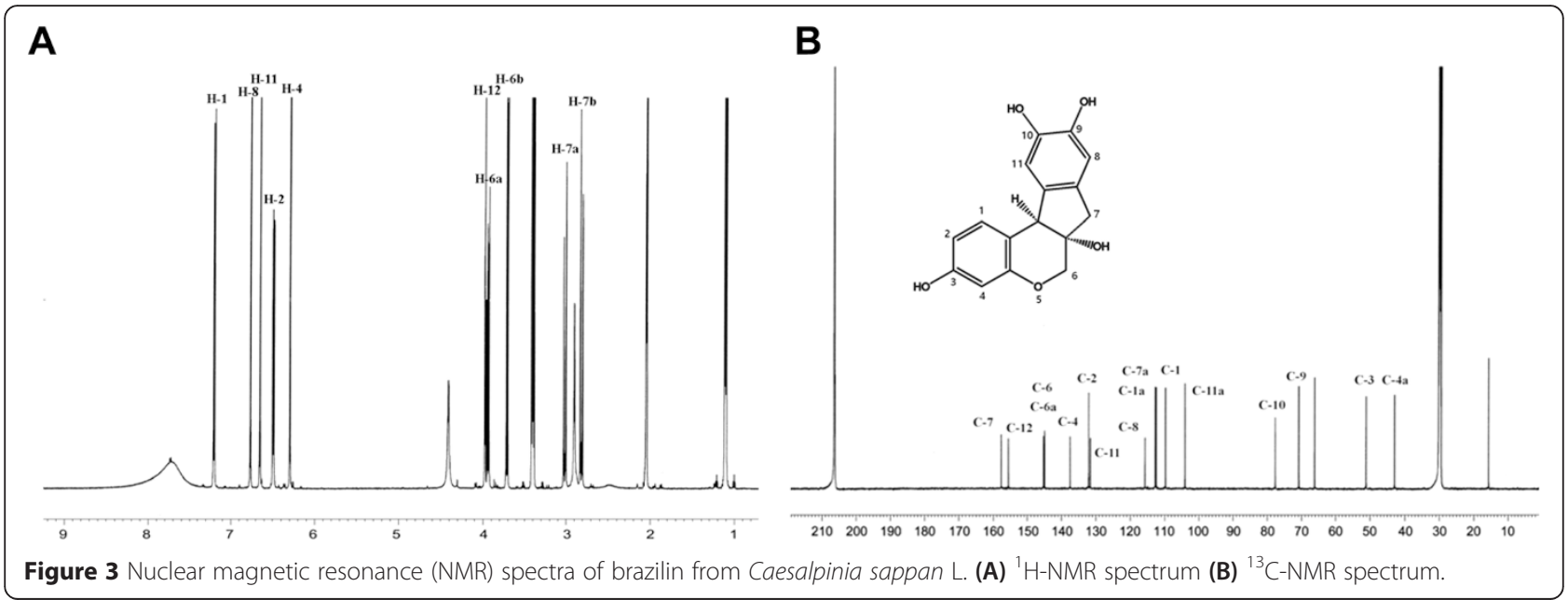




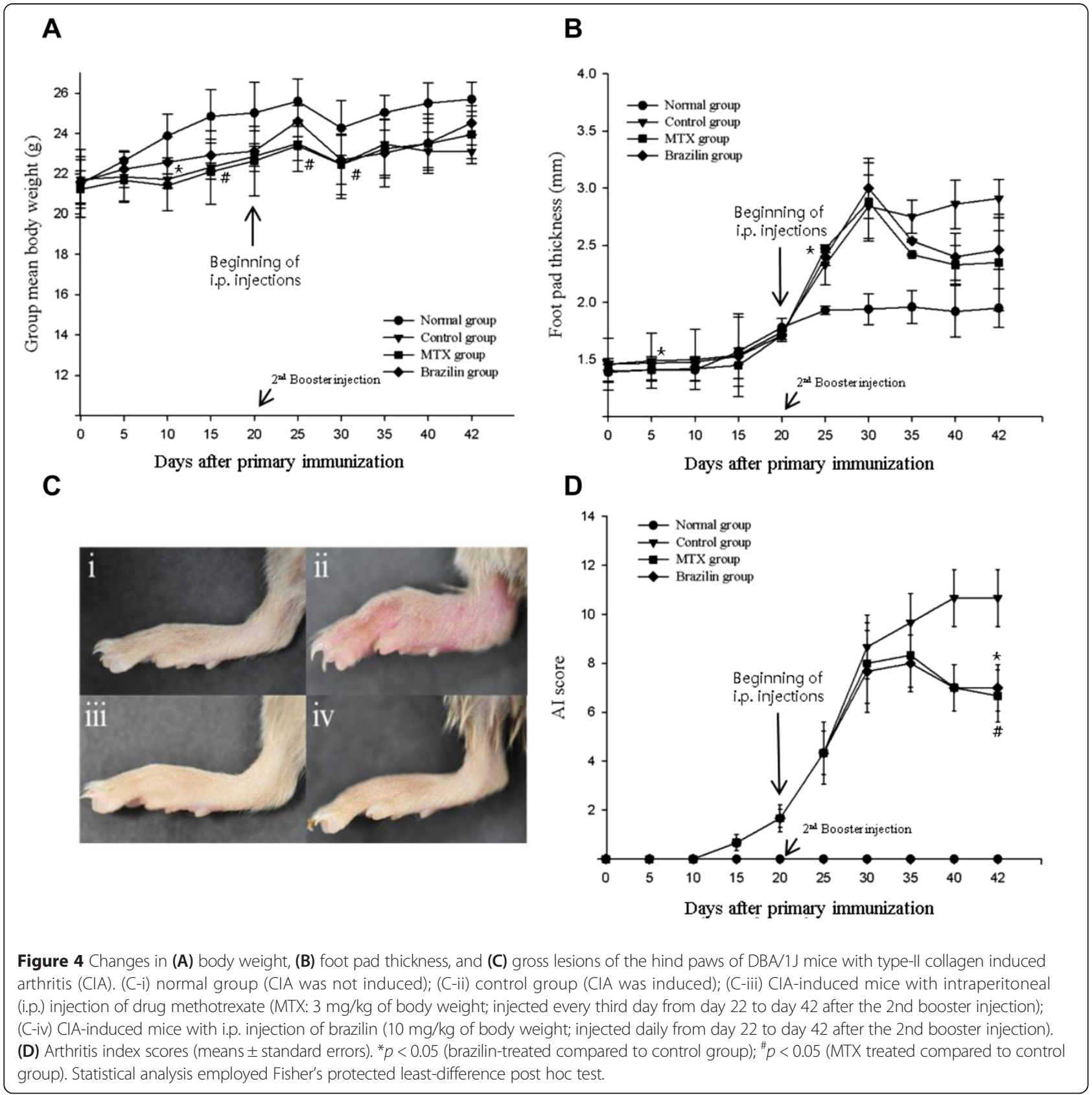

separation (Tb.Sp) was lower in the normal group than in the groups in which CIA was induced.

Effects of brazilin on serum cytokine and enzyme levels in $\mathrm{CIA}$ mice

The serum levels of the proinflammatory cytokines TNF- $\alpha$, IL-1 $\beta$, and IL- 6 in CIA-induced mice are shown in Figure 7. Serum cytokine levels in the CIA-induced control group were significantly higher than those in the normal group on day 42. Significant reductions in the cytokine levels were evident upon treatment with either MTX or brazilin, compared to the control group.
Although the levels of TNF- $\alpha$, IL-1 $\beta$, and IL- 6 in serum were not significantly different between MTX or brazilin administered groups, we observed reduced-level of serum cytokines in these groups when compared with control group.

\section{Effects of brazilin on organ weights and biochemical parameters in $\mathrm{CIA}$ mice}

Brazilin caused marginal weight loss in CIA-induced mice compared to normal animals, but this was not accompanied by any observable toxicity. Relative organ weight means that the organ weight is based on proportionality. In such 


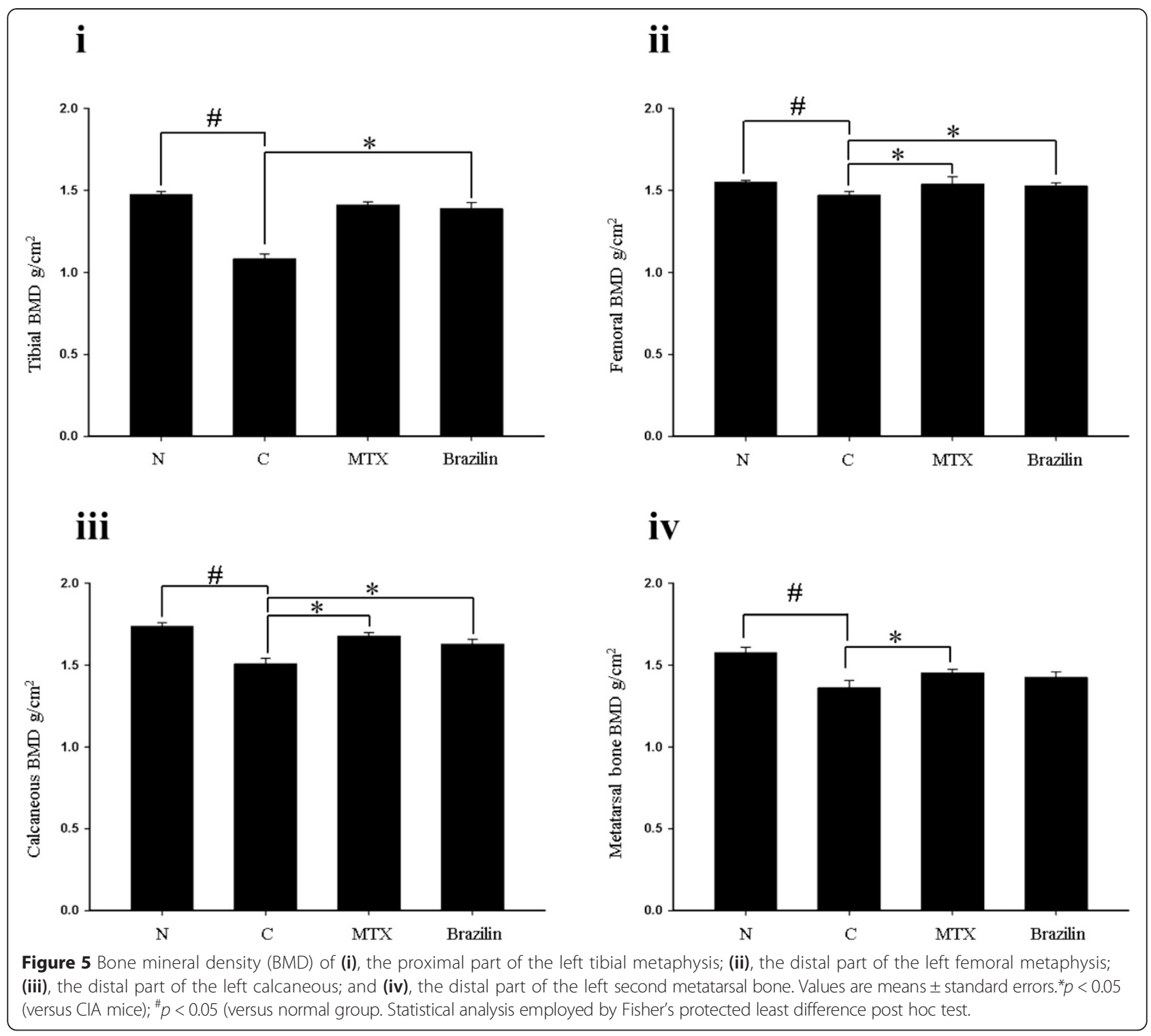

cases, organ weights are normalized by body weight, thereby permitting comparison of organs from animals with different body weights. The liver-to-body weight ratios of control group against normal group was $6.01 \pm 0.48$, whereas MTX and brazilin administrated groups were $4.84 \pm 0.62$, and $6.03 \pm 0.72$, respectively. The kidney-tobody-weight ratio in control group was $1.98 \pm 0.11$, while MTX and brazilin were $1.63 \pm 0.11$ and $1.92 \pm 0.13$, respectively. In brazilin-administered group, no significant changes were found in liver, kidney, and spleen organ-tobody weights (Table 2). Serum AST levels were higher in the control group than the normal group, and brazilin caused a marginal reduction in AST levels. Higher ALT levels were evident in the CIA-induced control group compared to normal group. Administration of brazilin to CIA-induced mice caused the ALT level to be maintained at a level greater than the control group. Mice given MTX did not show an appreciable rise in ALT levels, compared to brazilin-treated animals. ALP levels were also higher in CIA-induced mice (compared to normal and control) after treatment with either MTX or brazilin. Thus, brazilin, a natural component of the heartwood extract of $C$. sappan, effectively regulated stress levels after induction of type-II CIA.

\section{Discussion}

C. sappan (Leguminosae) is an herb exhibiting ethnomedical properties [22]. The herb is distributed in Southeast Asian countries, including China, India, Burma, Thailand, Indonesia, and Vietnam. The heartwood of the plant has traditionally been used as an analgesic [23], although antioxidative [24], anti-inflammatory [25-27], antibacterial 


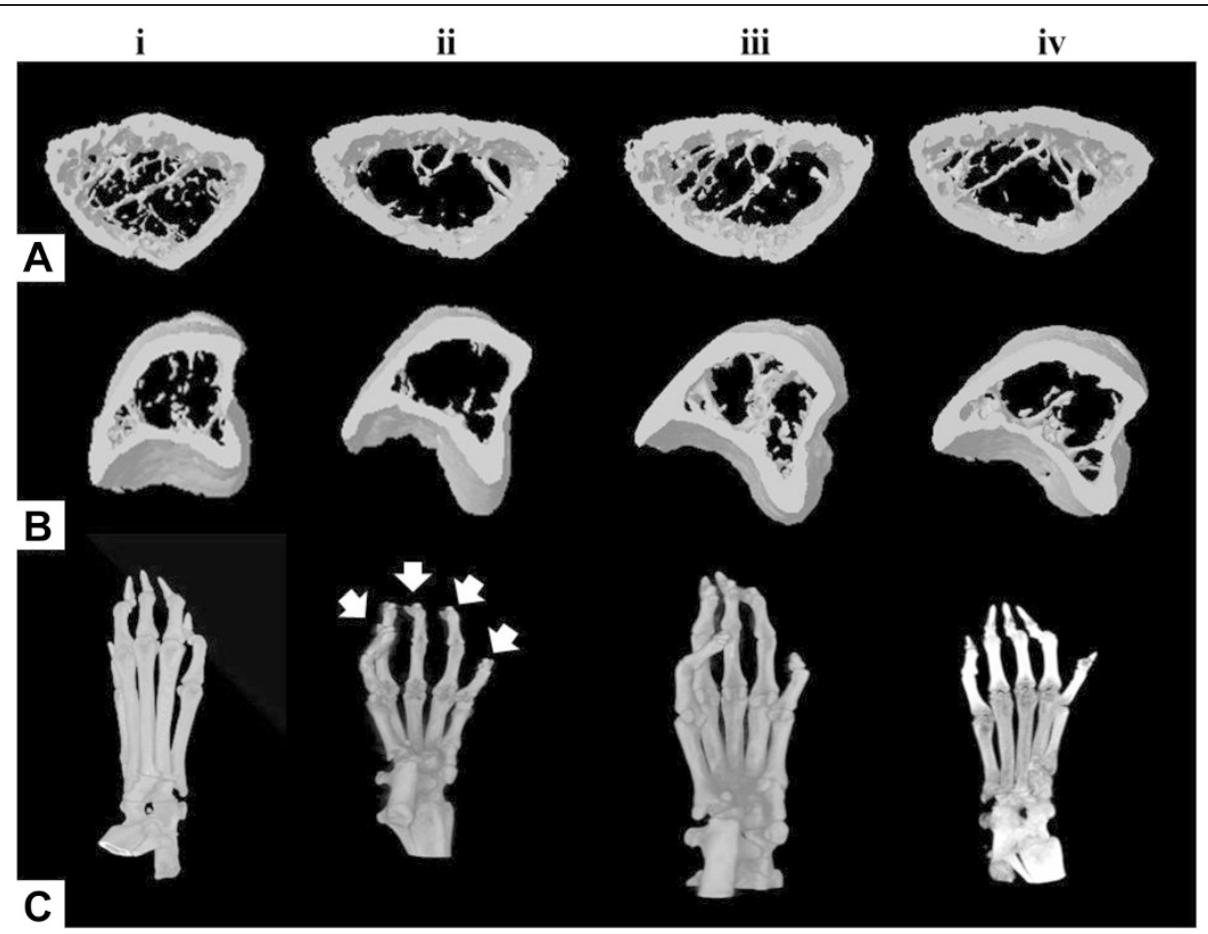

Figure 6 Microfocal computed tomography (micro-CT) images of DBA/1J mice with collagen-induced arthritis (CIA). A, the proximal part of the left tibial metaphysis; $\mathbf{B}$, the distal part of the left femoral metaphysis; $\mathbf{C}$, the left leg. (i) normal group (CIA was not induced); (ii) control group (CIA was induced); (iii) CIA-induced mice treated with methotrexate (MTX); (iv) CIA mice treated with brazilin.

[28,29], and anticonvulsive [25] activities have also been reported. C. sappan extracts have been shown to exert an anti-osteoporotic activity, and also anti-inflammatory actions on osteoarthritic chondrocytes and synovial macrophages [30,31]. The plant is a rich resource of flavonoids [32] and phenolics including prostosappanins A-E, sappanchalcone, 3-deoxysappanone, 7, 3', 4'-trihydroxy-3benzyl-2H-chromene, and others [33,34]. Brazilin exhibits various biological activities including anti-hyperglycemic [15], anti-hepatotoxic [14], and anti-inflammatory effects [17]. Earlier reports also suggested that, in vitro, brazilin decreased the levels of mRNAs encoding proinflammatory cytokines such as TNF- $\alpha$ and IL-6 [35]. Indeed, studies have shown that immune cell lines, including RAW 264.7 mouse macrophages, mouse macrophage-like J774.1 cells and THP-1 cells, produce proinflammatory cytokines, chemokines, and other proinflammatory mediators results in an inflammatory environment that drives the upregulation of cartilage-degrading matrix metalloproteinases (MMPs), disintegrin, and metalloproteinase with thrombospondin motifs (ADAMTS) [36]. It was reported that brazilin obtained from an ethanolic Caesalpinia sappan extract (CSE) inhibited the expression of proinflammatory cytokines IL- $1 \beta$ and TNF- $\alpha$ in IL-1 $\beta$-stimulated chondrocytes and LPS-stimulated THP-1 macrophages [30].

Brazilin was the principal component of the most active fraction obtained after sequential purification of C. sappan extracts via Sephadex and silica gel chromatography, and yielded a near-homogenous HPLC peak. Subsequently, the structure thereof was elucidated via MS and NMR spectroscopy. In a previous study, nine compounds from C. sappan purified by silica gel chromatography included

Table 1 Microstructure of cancellous bone at the distal part of the left femur

\begin{tabular}{lllllll}
\hline Groups $(\boldsymbol{n}=\mathbf{1 0})$ & BV/TV (\%) & BS/BV $(\mathbf{m m})$ & Tb.Th $(\mathbf{m m})$ & Tb.N $\left(\mathbf{m m}^{\mathbf{- 1}}\right)$ & Tb.Sp $(\mathbf{m m})$ & Fractal dimension \\
\hline Normal & $35.02 \pm 2.65$ & $18.83 \pm 3.22$ & $0.106 \pm 0.004$ & $3.30 \pm 0.23$ & $0.20 \pm 0.03$ & $2.49 \pm 0.021$ \\
Control & $28.41 \pm 1.47^{*}$ & $23.36 \pm 3.15^{*}$ & $0.086 \pm 0.004^{*}$ & $3.32 \pm 0.74$ & $0.22 \pm 0.05$ & $2.39 \pm 0.071$ \\
MTX & $33.38 \pm 3.12^{*}$ & $19.71 \pm 2.71^{*}$ & $0.102 \pm 0.003^{* \#}$ & $3.29 \pm 0.23^{* \#}$ & $0.20 \pm 0.04$ & $2.46 \pm 0.052$ \\
Brazilin & $32.53 \pm 4.03^{*}$ & $20.23 \pm 3.13^{*}$ & $0.099 \pm 0.006^{* \#}$ & $3.29 \pm 0.21^{*}$ & $0.21 \pm 0.02$ & $2.41 \pm 0.041$ \\
\hline
\end{tabular}

Four groups of mice ( $n=10$ each) were evaluated: control mice without collagen-induced arthritis (CIA) (normal) and CIA mice treated with saline (control group), with therapeutic administration of methotrexate (MTX: $3 \mathrm{mg} / \mathrm{kg}$ of body weight; injected every third day from day 22 to day 42 after 2 nd booster injection) or brazilin ( $10 \mathrm{mg} / \mathrm{kg}$ of body weight; injected daily from day 22 to day 42 after the 2 nd booster injection). BV - bone volume; TV - tissue volume; BS - bone surface; Tb.Th - trabecular thickness; Tb.N - trabecular number; Tb.Sp - trabecular separation; ${ }^{*} p<0.05$ versus normal group. ${ }^{\#} p<0.05$ versus control group. 

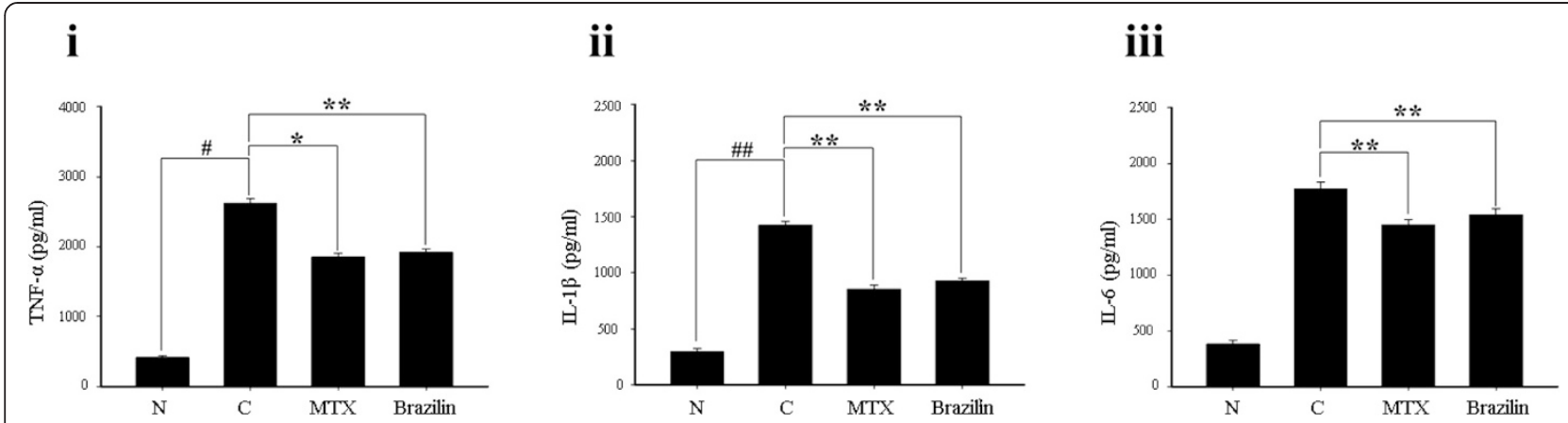

Figure 7 Effects of brazilin from Caesalpinia sappan L. on serum tumor necrosis factor (TNF-a) (i), interleukin (IL)-1 13 (ii), and IL-6 (iii), levels. On day 42 post-administration, the levels of inflammatory cytokines in mouse sera were determined via enzyme-linked immunosorbent assays. Data are expressed as means \pm standard errors; $n=10$ in each group. ${ }^{* *} p<0.001,{ }^{*} p<0.05$, versus control group mice with $C I A ; ~ \# \#<0.001,{ }^{\#} p<0.05$, versus normal mice.

brazilin and sappanchalcone, protosappanin, 3-(3', 4'dihydroxybenzyl)-7-hydroxy chroman-4-one, episappanol, 4-O-methylepisappanol, 4-O-methylsappanol, 3-deoxysapp anchalcone, and 4-(7-Hydroxy-2,2-dimethyl-93H-1,3,5-trio xa-cyclopenta[ $\alpha]$ naphthalene-3 $\alpha$-yl-methyl)-benzene-1,2-di ol. Brazilin was earlier isolated from an ethyl acetate extract of C. sappan using preparative HPLC with application of $100 \%$ methanol for $45 \mathrm{~min}$ [30], similar to our purification method. HPLC separations of methanol and ethanol extracts of C. sappan yielded peaks similar to those obtained upon HPLC of the n-hexane extract. All extracts stimulated osteoblast proliferation and exhibited anti-osteoporosis activities [31]. The spectral features of brazilin isolated from ethyl acetate extracts of $C$. sappan in the present study were in agreement with spectral profiles reported in the literature [25,37].

We studied the in vivo anti-inflammatory effects of brazilin in a collagen-induced arthritis (CIA) mice model. CIA mouse model can be used to explore human RA, because humans and mice are similar both genetically and immunologically [38]. CIA has been widely used as the animal model in RA research and demonstrated to resemble human RA more closely in terms of clinical, histological and immunological features, as well as genetic linkage, compared with other experimental arthritis models [39].

In a preliminary study, brazilin isolated from Caesalpinia sappan L. (Leguminosae) was implicated as a potent NF- $\mathrm{kB}$ inhibitor that selectively disrupts the formation of the upstream IL-1R signalling complex. Analysis of upstream signalling events revealed that brazilin markedly abolished the IL-1 $\beta$-induced polyubiquitination of IRAK1 and its interaction with IKK-G counterpart. Notably, pre-treatment of brazilin drastically interfered with the recruitment of the receptor-proximal signalling components including IRAK1/4 and TRAF6 onto MyD88 in IL-1R-triggerd NF- $\mathrm{kB}$ activation. Interestingly, brazilin did not affect the TNF-induced RIP1 ubiquitination and the recruitment of RIP1 and TRAF2 to TNFR1, suggesting that brazilin is effective in selectively suppressing the proximal signalling complex formation of IL-1R, but not that of TNFR1 [40].

We induced the development of chronic inflammation and closely monitored the effects thereof in terms of joint edema, erythema, and immobilization. The mean arthritis index score was 2.5-3.5 prior to administration of MTX

Table 2 Comparison of relative organ weights and biochemical parameters in DBA/1J mice with CIA

\begin{tabular}{|c|c|c|c|c|}
\hline Groups $(n=10)$ & Normal & Control & MTX & Brazilin \\
\hline \multicolumn{5}{|c|}{ Average relative organ weights (organ weight/body weight, \%) } \\
\hline Liver & $4.93 \pm 0.10$ & $6.01 \pm 0.48^{*}$ & $4.84 \pm 0.62$ & $6.03 \pm 0.72$ \\
\hline Kidney & $1.98 \pm 0.11$ & $1.95 \pm 0.32$ & $1.63 \pm 0.11^{*}$ & $1.92 \pm 0.13$ \\
\hline Spleen & $0.25 \pm 0.02$ & $0.48 \pm 0.14^{*}$ & $0.34 \pm 0.10$ & $0.56 \pm 0.21$ \\
\hline \multicolumn{5}{|l|}{ Biochemical parameters } \\
\hline AST(U/L) & $127.50 \pm 29.10$ & $172.50 \pm 30.51$ & $142.23 \pm 30.17$ & $145.00 \pm 32.71$ \\
\hline $\operatorname{ALT}(\mathrm{U} / \mathrm{L})$ & $32.00 \pm 2.83$ & $44.50 \pm 3.54^{*}$ & $43.33 \pm 12.58$ & $37.50 \pm 3.54^{*}$ \\
\hline Creatinine (mg/dL) & $0.53 \pm 0.11$ & $0.70 \pm 0.11$ & $0.55 \pm 0.05$ & $0.55 \pm 0.09$ \\
\hline
\end{tabular}

Organ coefficients (liver, kidney, and spleen) for DBA/1J mice treated with saline, MTX (3 mg/kg of body weight; injected every third day from day 22 to day 42 after 2nd booster injection) or brazilin ( $10 \mathrm{mg} / \mathrm{kg}$ of body weight; injected daily from day 22 to day 42 after the 2 nd booster injection). Statistical analysis was performed with a 2 -sample t-test comparing each sample group to the related normal group. Note: *denotes statistical significance at $p<0.05$ versus normal group. 
and/or brazilin. MTX, a DMARD, is commonly used to reduce inflammation and joint destruction in RA patients, but continuous prescription thereof may cause cytotoxic and genotoxic complications [41,42]. Our data shows that brazilin inhibits a higher RA disease progression in mice as compared to anti-rheumatic drug MTX. The serum levels of inflammatory mediators decreased after administration of brazilin in the present study that is in agreement to the several reports on attenuation of rat CIA by heartwood extracts of C. sappan [43].

Wang et al. reported that the ethanol extracts of C. sappan reduced the serum levels of proinflammatory cytokines including IL-1 $\beta$, IL-6, and TNF- $\alpha$ and expression of the COX-2 and NF- $\mathrm{kB}$ transcription factors in paw cartilage induced in CIA rat (Wistar strain) model [39]. The incidence of arthritis in CIA-susceptible strains of mice is generally very high, reaching $50-100 \%$ in most strains [44]. The arthritis incidence rate in male Wistar rat model was $10-75 \%[39,43]$, lower than $80-100 \%$ in the DBA/1J mouse model used in present study.

To evaluate adverse effects of brazilin, we physiologically monitored the arthritis disease development in mice in which CIA had been induced (control group), and in animals receiving MTX and/or brazilin, to assess whether the drugs might inhibit disease progression. We found that intraperitoneal administration of $10 \mathrm{mg} / \mathrm{kg}$ brazilin reduced paw swelling to a level comparable to that noted upon MTX treatment at a dose of $3 \mathrm{mg} / \mathrm{kg}$ body weight every 3rd day.

BMD volumes in CIA-induced control group were significantly lower, compared to test volumes, in the left tibial metaphysis, the distal part of the calcaneous, and the distal part of the metatarsal bone, but did not improve after administration of MTX or brazilin. The BMD decreases in control group may be attributable to increased bone surface erosion and decreased trabecular thickness. However, both bone volume and surface area were greater in the control group. These results agree with those of a study on BMD and micro-CT joint projection after administration of bisphosphonate, minodronic acid [45]. High-level bone turnover rate near joints was also observed in a model of carrageenan-induced arthritis [46]. Both suppression and reduction of BMD loss near joints are measures of anti-arthritic efficacy $[47,48]$. Suppression of bone surface erosion, and maintenance of trabecular thickness and the trabecular bone pattern, upon brazilin administration, reduced the extent of damage to both bone and joints. Therefore, brazilin from C. sappan maintained BMD and bone microstructure, without inhibiting mineralization.

\section{Conclusions}

We found that brazilin prepared from ethyl acetate extracts of C. sappan effectively reduced the serum levels of
TNF- $\alpha$, IL-1 $\beta$, and IL- 6 ; maintained the bone surface pattern; and decreased both paw swelling and the development of gross lesions, in the CIA mice model. These results suggest that brazilin derived from the heartwood of C. sappan may be useful to treat both RA and other inflammatory disorders.

\section{Abbreviations}

CIA: Collagen-induced arthritis; MTX: Methotrexate; RA: Rheumatoid arthritis; TNFa: Tumor necrosis factor a; IL: Interleukin; NSAIDs: Non-steroidal anti-inflammatory drugs; DMARDs: Disease modifying anti-rheumatic drug; LC-MS-IT-TOF: Liquid chromatography-mass spectrometer inductively coupled-time of flight; NMR: Nuclear magnetic resonance; CFA: Complete freund adjuvant; ICFA: Incomplete freund adjuvant; BMD: Bone mineral density; AST: Aspartate transaminase; ALT: Alanine transaminase; ALP: Alkaline phosphatase; Fr: Fraction.

\section{Competing interests}

The authors declare that they have no competing interests.

\section{Authors' contributions}

EGJ performed the experiments, analyzed the data, and wrote the paper. $\mathrm{KIH}, \mathrm{SGH}$ and HJK performed the experiments and analyzed the data. BBP wrote the paper and analyzed the data. YHK provided technical details and results validation. $\mathrm{MDH}$ designed the experiments, analyzed the data, provided technical details, and wrote the paper. All authors read and approved the final manuscript.

\section{Acknowledgements}

This study was supported, in part, by the Soonchunhyang University Research Fund.

\section{Author details}

'Department of Life Science and Biotechnology, Soonchunhyang University, Asan, Chungnam 336-745, Republic of Korea. ${ }^{2}$ Department of Dental hygiene, Gimcheon University, 214 Daehakro, Gimcheon City Gyungbuk 740-704, Korea. ${ }^{3}$ Division of Plant Biotechnology, College of Agriculture and Life Science, Chonnam National University, Gwangju 500-757, Republic of Korea. ${ }^{4}$ School of Biotechnology, Trident Academy of Creative Technology (TACT), Bhubaneswar 7510070disha, India.

Received: 15 November 2014 Accepted: 13 April 2015

Published online: 22 April 2015

\section{References}

1. Klareskog L, Catrina Al, Paget S. Rheumatoid arthritis. Lancet. 2009;373:659-72.

2. Mahajan TD, Hooker R, Maher L, Brown G, Reimold A. Abatacept therapy for rheumatoid arthritis in the setting of hepatitis C infection. J Clin Rheum. 2010;16:332-4

3. Corvaisier M, Delneste $Y$, Jeanvoine $H$, Preisser L, Blanchard S, Garo E, et al. $\mathrm{L}-26$ is overexpressed in rheumatoid arthritis and induces proinflammatory cytokine production and Th17 cell generation. PLoS Biol 2012, 10:10.1371/ annotation/22e63f1f-1a6e-4d53-8d33-06527d9a1dd4.

4. Van der Berg WB, Joosten LA, Kollias G, Van De Loo FA. Role of TNF-1 in experimental arthritis: separate activity of IL-1 J in chronicity and cartilage destruction. Ann Rheum Dis. 1999;58(suppl I):SI40-8.

5. Lubberts E, Joosten LA, Oppers B, van den Bersselaar L, Coenen-de Roo CJ, Kolls JK, et al. IL-1 independent role of IL-17 in synovial inflammation and joint destruction during collagen-induced arthritis. J Immunol. 2001;167:1004-13.

6. Chu SY, Yeter K, Kotha R, Pong E, Miranda Y, Phung S, et al. Suppression of rheumatoid arthritis B cells by XmAb5871, an anti-CD19 antibody that engages $B$ cell antigen receptor and FcyRIllb inhibitory receptor. Arthrit Rheum. 2013;66:1153-64.

7. Ahmed S, Anuntiyo J, Malemud CJ, Haqqi TM. Biological basis for the use of botanicals in osteoarthritis and rheumatoid arthritis: A review. Evi Based Complement Alternat Med. 2005;2:301-8.

8. Shahin AA, Ismail MM, Saleh AM, Moustafa HA, Aboul-Ella AA, Gabr HM. Protective effect of folinic acid on low-dose methotrexate genotoxicity. J Rheum. 2001;60:63-8. 
9. Hoekstra M, Haagsma CJ, Doelman CJ, van der Laar MA. Intermittent rises in plasma homocysteine in patients with rheumatoid arthritis treated with higher dose methotrexate. Ann Rheum Dis. 2005;64:141-3.

10. Sekeroglu ZA, Sekeroglu V. Effects of Viscum album L. extract and quercetin on methotrexate-induced cyto-genotoxicity in mouse bone-marrow cells. Mut Res. 2012;746:56-9.

11. Cai X, Zhou H, Wong YF, Xie Y, Liu ZQ, Jiang ZH, et al. Suppression of the onset and progression of collagen-induced arthritis in rats by QFGJS, a preparation from an anti-arthritic Chinese herbal formula. J Ethnopharmacol. 2007;110:39-48.

12. Mirjalili MH, Moyano E, Bonfill M, Cusido RM, Palajon J. Steroidal lactones from Withenia somnefera, an ancient plant for novel medicine. Molecules. 2009;14:2373-93.

13. Joseph B, Raj SJ. Pharmacognostic and phytochemical properties of Aloe vera. Int J Pharma Sci Rev Res. 2010;4:106-0.

14. Moon CK, Park KS, Kim SG, Won HS, Chung JH. Brazilin protects cultured rat hepatocytes from $\mathrm{BrCCl}_{3}$-induced toxicity. Drug Chem Toxicol. 1992;15:81-91.

15. Kim SG, Kim YM, Khil LY, Jeon SD, So DS, Moon CH, et al. Brazilin inhibits activities of protein kinase $C$ and insulin receptor kinase in rat liver. Arch Pharma Res. 1998;21:140-6.

16. Hu CM, Kang JJ, Lee CC, Li CH, Liao JW, Cheng YW. Induction of vasorelaxation through activation of nitric oxide synthase in endothelial cells by brazilin. Eur J Pharmacol. 2003:468:37-45.

17. Bae IK, Min HY, Han AR, Seo EK, Lee SK. Suppression of lipopolyssacharideinduced expression of inducible nitric oxide synthase by brazilin in RAW 264.7 macrophage cells. Eur J Pharmacol. 2005;513:237-42.

18. Chang Y, Huang SK, Lu WJ, Chung CL, Chen WL, Lu SH, et al. Brazilin isolated from Caesalpinia sappan L. acts as a novel collagen receptor agonist in human platelets. J Biomed Sci. 2013;20:4.

19. Namikoshi M, Nakata H, Nuno M, Ozawa T, Saitoh T. Homoisoflavonoids and related compounds. III. Phenolic constituents of Caesalpinia japonica SIEB. et ZUCC. Chem Pharm Bull. 1987;35:3568-75.

20. Zimmerman DH, Taylor P, Bendele A, Carambula R, Duzant $Y$, Lowe V, et al. CEL-2000: A therapeutic vaccine for rheumatoid arthritis arrests disease development and alters serum cytokine/chemokine patterns in the bovine collagen type II induced arthritis in the DBA mouse model. Int Immunopharmacol. 2010;10:412-21.

21. Zalevsky J, Secher T, Ezhevsky SA, Janot L, Steed PM, O'Brien C, et al. Dominant-negative inhibitors of soluble TNF attenuate experimental arthritis without suppressing innate immunity to infection. J Immunol. 2007;179:1872-83.

22. Uphof JC. Dictionary of Economic Plants. 2nd ed. New York: Lubrecht and Cramer Ltd. USA; 1968. p. 93-4.

23. Soka T. Dictionary of Chinese drugs. Tokyo: Shanghai Science Technology Shogaukan, Shogakukan Press; 1985. p. 1627-8.

24. Badami S, Moorkoth S, Rai SR, Kannan E, Bhojraj S. Antioxidant activity of Caesalpinia sappan heartwood. Biol Pharm Bull. 2003;26:1534-7.

25. Baek NI, Jeon SG, Ahn EM, Hahn JM, Bahn JH, Jang JS, et al. Anti-convulsant compounds from the wood of Caesalpinia sappan L. Arch Pharmacol Res. 2000;23:344-8

26. Ye M, Xie WD, Lei F, Meng Z, Zhao YN, Su H, et al. Brazilein, an important immunosuppressive component from Caesalpinia sappan L. Int Immunopharmacol. 2006;64:26-432.

27. Jeong IY, Jin CH, Park YD, Lee HJ, Choi DS, Byun MW, et al. Anti-inflammatory activities of an ethanol extract of Caesalpinia sappan L. in LPS-induced RAW 264.7 cells. J Food Sci Nutr. 2008;13:253-8.

28. Xu HX, Lee SF. The antibacterial principle of Caesalpinia sappan. Phytotherapy Res. 2004;18:647-51.

29. Lim MY, Jeon J, Jeong EY, Lee CH, Lee HS. Antimicrobial activity of 5-hydroxy-1, 4-naphthoquinone isolated from Caesalpinia sappan toward intestinal bacteria. Food Chem. 2007;100:1254-8

30. Wu SQ, Otero M, Unger FM, Goldring MB, Phrutivorapongkul A, Chiari C, et al. Anti-inflammatory activity of an ethanolic Caesalpinia sappan extract in human chondrocytes and macrophages. J Ethnopharmacol. 2011;138:364-72.

31. Subehan S, Rifai Y, Mufidah. The characterization of anti-osteoporotic activity of Sappan Ligum (Caesalpinia sappan L.) extracts. Int J Phytomed. 2013;5:7-13.

32. Xie YW, Ming DS, Xu HX, Dong H, Butt PP. Vasorelaxing effects of Caesalpinia sappan: involvement of endogenous nitric oxide. Life Sci. 2000;67:1913-8.
33. Batubara I, Mitsunaga T, Ohashi H. Brazilin from Caesalpinia sappan wood as an anti-acne agent. Japan Wood Res Soc. 2009;56:77-81.

34. Liu AL, Shu SH, Qin HL, Lee SM, Wang YT, Du GH. In vitro anti-influenza viral activities of constituents from Caesalpinia sappan. Planta Medica. 2009;75:337-9.

35. Shen J, Zhang H, Lin H, Su H, Xing D, Du L. Brazilein protects the brain against focal cerebral ischemia reperfusion injury correlating to inflammatory response suppression. Eur J Pharmacol. 2007:558:88-95.

36. Goldring MB, Goldring SR. Osteoarthritis. J Cell Physiol. 2007;213:626-34.

37. Fu LC, Huang XA, Lai ZY, Hu YJ, Liu HJ, Cai XL. A new 3-benzylchroman derivative from Sappan Ligum (Caesalpinia sappan). Molecules. 2008;28:1923-30.

38. Zhang P, Han D, Tang T, Zhang X, Dai K. Inhibition of the development of collagen-induced arthritis in Wistar rats through vagus nerve suspension: a 3-month observation. Inflammat Res. 2008;57:322-8.

39. Wang YZ, Sun SQ, Zhou YB. Extract of the dried heartwood of Caesalpinia sappan L. attenuates collagen-induced arthritis. J Ethnopharmacol. 2011;136:271-8.

40. Jeon J, Lee JH, Park KA, Byun HS, Lee H, Lee $Y$, et al. Brazilin selectively disrupts proximal IL-1 receptor signalling complex formation by targeting an IKK-upstream signalling components. Biochem Pharmacol. 2014;89:515-25.

41. Li JC, Kaminskas E. Accumulations of DNA strand break and methotrexate cytotoxicity. Proc Nat Acad Sci USA. 1984;81:5694-8.

42. Egan LJ, Sandborn WJ. Methotrexate for inflammatory bowel disease: pharmacology and preliminary results. Mayo Clinic Proc. 1996;71:69-80.

43. Culigan TE, Krinsbeek AM, Margulis DH, Sherach EM, Strober W. Adjuvant arthritis in the rat. In: Current Protocols in Immunology. New York: John Wiley \& Sons Inc; 1996.

44. David DB, Kary AL, Edward FR. Collagen-induced arthritis. Nature Protocols. 2007;2:1269-75.

45. Yamane I, Hagino H, Okano T, Enokida M, Yamasaki D, Teshima R. Effect of Minodronic acid (ONO-5920) on bone mineral density and arthritis in adult rats with collagen-induced arthritis. Arthrit Rheum. 2003:48:1732-41.

46. Moran EL, Fornasier TL, Bogoch TR. Pamidronate prevents bone loss associated with carrageenan arthritis by reducing resorptive activity but not recruitment of osteoclasts. J Orthopaedic Res. 2000;18:873-81.

47. Miller PD, Bonnick SL, Johnston CC, Kleerekoper M, Lindsay RL, Sherwood $L M$, et al. The challenges of peripheral bone density testing: Which patients need additional central density skeletal measurements? J Clin Densitomet. 1998;1:211-7.

48. Podworny NV, Kandel RA, Renlund RC, Grynpas MD. Partial chondroprotective effect of zoledronate in a rabbit model of inflammatory arthritis. J Rheum. 1999;26:1972-82

\section{Submit your next manuscript to BioMed Central and take full advantage of:}

- Convenient online submission

- Thorough peer review

- No space constraints or color figure charges

- Immediate publication on acceptance

- Inclusion in PubMed, CAS, Scopus and Google Scholar

- Research which is freely available for redistribution 